\title{
Change of Title: Sinusitis Becomes Sinusitis and Asthma
}

\section{César Picado}

Department of Pneumology and Respiratory Allergy Hospital Clinic, University of Barcelona, Vilarroel 170, 08036 Barcelona, Spain; cpicado@ub.edu

Sinusitis journal released its first Volume in 2016. Since then, the journal has published 25 articles on the topic of rhinitis, rhinosinusitis, nasal polyps, surgery in diseases of the upper airways, and new techniques and methods to investigate and treat upper airways disease.

Numerous studies conducted in the last two decades show the close relationship that exists between diseases of the upper and lower airways, which are frequently present in the same patient. Numerous studies have also shown that the mechanisms responsible for inflammatory processes that affect the upper and lower airways share similar etiopathogenic mechanisms. Together, these observations support the notion of a bidirectional "unified airway" respiratory inflammation model based on epidemiological, clinical, and etiological upper and lower airway connections.

One of the clearest examples of this association is the epidemiological and clinical relationship between diseases of the upper airways (rhinitis, rhinosinusitis) with asthma. Although many aspects of this relationship are known, there are still many more that remain to be clarified, such as the difference in the remodeling of the upper and lower areas in front of the same inflammatory process, the impact of the medical or surgical intervention on diseases of the upper airways over that of the lower airways, and the role of new biological therapies in the treatment of inflammatory airway diseases affecting both upper and lower airways.

In order to bring the scope of the journal Sinusitis closer to the medical reality, in which diseases of the airways very often do not occur in isolation, but in close association with processes affecting the lower airways-especially in asthma-it has been considered appropriate to change the name of the journal by adding Asthma to the current title.

On behalf of the Editorial Board and the Editorial Office, I wish to thank all authors, reviewers and external editors for their support to Sinusitis over the past years, and welcome them to join us in developing Sinusitis and Asthma as one of the leading reference journals focused on the study of diseases affecting the whole respiratory track.

(C) 2018 by the author. Licensee MDPI, Basel, Switzerland. This article is an open access article distributed under the terms and conditions of the Creative Commons Attribution (CC BY) license (http:/ / creativecommons.org/licenses/by/4.0/). 